\title{
EL MUEBLE EN LA NOVELA CORTA DEL SIGLO DE ORO: ALGUNAS REFLEXIONES EN TORNO A LA CAMA
}

\author{
Fernando Copello JouAnchin \\ Université du Maine, Le Mans \\ Fernand.Copello@univ-lemans.fr
}

La cama sin sueño es teatro de peligrosísimas representaciones...

(Juan de Zabaleta, El día de fiesta por la mañana, 1654)

...sin ti mi cama es ancha...

(Joan Manuel Serrat, Romance de Curro el Palmo, 1974)

\begin{tabular}{l} 
n el año 1931, Victoria Ocampo, directora de la revista Sur, que quizá haya \\
sido la revista literaria de mayor peso en la América Latina de la primera \\
mitad del siglo xx, inauguraba el primer número participando en él con un \\
trabajo dedicado al mueble (Ocampo 1931: 167-174). Esa elección temática debió \\
de sorprender y hasta quizá algunos pudieran pensar que esa mujer, "mujer al fin", \\
no podía interesarse más que en frivolidades. Sin embargo, la amiga de Ortega y \\
Gasset, creaba allí nuevos rumbos que hoy aceptamos como absolutamente natu- \\
rales: hablar de muebles, de espacios, de decoración es también hablar de litera- \\
tura. Por un lado, hablar de muebles es admitir que el detalle tiene en el conjunto \\
de un texto literario un peso evidente, y de ello dan prueba los estudios que abren \\
perspectivas desde la crítica pictórica (Arasse 1996). Por otra parte, hablar de \\
muebles entronca con aspectos sociales e históricos que despiertan un evidente \\
interés desde hace ya largo tiempo. Y, por último, no podemos dejar de pensar \\
en el mueble al abordar aspectos partextuales o evocar el libro como objeto. Un \\
libro es de alguna manera un mueble que contiene textos e ilustraciones, títulos \\
y dedicatorias como si fueran cajones, estanterías y ornamentos ${ }^{1}$. Los estudios \\
presentados en un reciente número de Ínsula dedicado a los espacios domésticos \\
11 Siguiendo esta perspectiva he intentado acercarme recientemente a un libro de fábulas (Copello \\
2013). \\
\hline
\end{tabular}

Edad de Oro, XXXIII (2014), pp. 383-394, ISSN: 0212-0429 
en la literatura áurea se acercan por momentos al paisaje mobiliario (Santo Tomás 2006) y no evitan estas perspectivas trabajos interesados por la sociabilidad en la novela corta que evocan la cultura material al hablar de un espacio de orden estético (Albert 2013).

Creo que estas líneas pueden servir de justificación antes de comenzar un análisis muy breve que solo pretende abrir una puerta. Puesto a elegir un mueble, entre los tantos que habitan la novela corta, se me ha ocurrido que la cama contiene en sí una problemática rica y compleja extremadamente seductora. La cama es a la vez un mueble y un espacio para estar en el que se practican actividades diversas, casi todas ellas relacionadas con el reposo y el ocio. La cama parece estar delimitando un espacio no laboral, y digo parece porque en ciertos medios nobiliarios la cama podía ser también un sitio dedicado a la negociación y al intercambio político, como en el caso de ciertas prácticas de la monarquía (Perrot 2009: 27-51). Las muy diversas situaciones posibles que transcurren en la cama o desde la cama se relacionan siempre con un espacio de intimidad o confianza, verdaderas o simuladas. La cama es generalmente el punto central dentro de un área mayor: la alcoba. La alcoba contiene la cama y la cama contiene el o los cuerpos. En un trabajo reciente sobre las Novelas ejemplares de Cervantes, Alejandra Koper nos dice: «Las casas y los cuerpos de los personajes se prefiguran y se constituyen mutuamente» (Koper 2013: 99). Evoca también lo que ella llama casas de fertilidad y casas de curación. Algo semejante podríamos decir de las camas, que se relacionan con estos dos aspectos del vivir. La cama es ese ámbito en el que el cuerpo cobra un protagonismo particular.

Ese protagonismo aparece hoy muy relacionado con la sexualidad. Me resulta interesante ver la evolución del verbo encamarse que, en el castellano clásico, significaba: «Meterse en la cama. Es voz del estilo familiar, formada de la preposición En, y el nombre Cama» (Autoridades 1990: III, 427 b); y que en el lunfardo rioplatense del siglo xx cobra la acepción siguiente: «V. Acostarse para copular» (Vaccaro 1976: 52). Ello muestra que la connotación sexual y/o amorosa le da en nuestros días una coloración particular al espacio del lecho, que aparece también en el verso de Joan Manuel Serrat que nos sirve de epígrafe: la cama es hoy, en su mejor sentido, un lugar para dos.

¿Qué significado le atribuyen los lexicógrafos de la España clásica al vocablo cama? Si recorremos el Tesoro de la lengua castellana de Covarrubias, publicado en 1611 (es decir, en la España postridentina y en un momento inmediatamente anterior al del auge de la novela corta), nos encontramos con una larga definición del término cama que le otorga fundamentalmente un valor relacionado con el descanso, la enfermedad y la muerte: «Es el lecho en que nos echamos para dormir y descansar del trabajo y la vigilia», versa la definición inicial (Covarrubias 1995: 241 a y b). Luego el texto completa esta primera apreciación estableciendo 
un vínculo entre el sueño y la muerte; más adelante se habla de la enfermedad, que lleva al hombre a «caer en la cama». En ningún momento se evoca la relación con la sexualidad y tampoco con la fertilidad. No va más lejos el artículo lecho, en donde se dice: «el lugar donde nos recostamos para dormir y descansar» (Covarrubias 1995: $705 \mathrm{a} \mathrm{y} \mathrm{b).}$

En el más tardío Diccionario de Autoridades la definición comienza de una manera similar: «Cama. s. f. El lecho que sirve para dormir, para descansar, o para curarse uno cuando está enfermo» (Autoridades 1990: II, 82 a). Curiosamente uno de los ejemplos citados proviene del Quijote y, si bien alude a un momento de erotismo frustrado, no deja por ello de evocar la relación entre la cama y la sensualidad: «Don Quijote la sintió y [...] en la cama tendió los brazos para recibir a la hermosa doncella» (Autoridades 1990: II, 82 a y b). Es evidente que cierto colorido sexual tiñe la palabra cama, aunque ello no se diga de manera explícita. No va más lejos la definición de lecho: «El lugar o cama donde nos recostamos para dormir y descansar» (Autoridades 1990: IV, 375b).

Pero los diccionarios no deberían llevarnos a oscurecer o disfrazar lo que sin duda ocurría en la percepción de este vocablo en el siglo xviI. El siglo anterior, cuyas huellas siguen estando ampliamente presentes, subraya con intensidad (y citaré dos ejemplos provenientes de la narrativa) la relación entre la cama y el placer. El primer ejemplo proviene de Tirant lo Blanc, libro de caballerías elogiado por Cervantes, en el cual la doncella Estefanía nos dice:

... quando la doncella ama al gentilhombre e cavallero por su deleite, el qual es abundoso de palabras graciosas e apuestas que os den vida por un año; e si de allí adelante passan y pueden llegar a la cama muy entoldada y las sávanas bien perfumadas, e toda una noche de ynvierno pueden estar, tal amor como este me parece mui mejor que ninguno de los otros².

El segundo ejemplo procede de una novela corta española, aquella que, en cierto sentido, inaugura el género: El Abencerraje y la hermosa Jarifa. El episodio que evoco comienza con un diálogo entre Jarifa y Abindarráez: «Ella le tomó por la mano y le metió en una cámara secreta. Y sentándose sobre una cama que en ella había, le dijo...» (El Abencerraje 1965: 39). Vemos allí el preámbulo de lo que va a ser un encuentro carnal. Se trata del itinerario clásico de la seducción cuyo recorrido espacial se caracteriza por una penetración que va de la casa a la alcoba, de la alcoba a la cama y dentro de la cama a los cuerpos ${ }^{3}$. El paso siguiente está claramente aludido:

Citado por Roubaud (1985). Véase Tirante el Blanco (1974: II, 170-171). El subrayado es nuestro. Sobre este aspecto cito una frase del ensayo de Perrot (2009: 363): «On penètre dans les profondeurs de la maison en même temps que dans celles du corps» . 
El moro la tomó entre sus brazos y besándola muchas veces las manos por la merced que le hacía, la dijo: «Señora mía, en pago de tanto bien como me habéis ofrecido, no tengo que daros que no sea vuestro, sino sola esta prenda en señal que os recibo por mi señora y esposa».

Y llamando a la dueña se desposaron. Y siendo desposados se acostaron en su cama, donde con la nueva experiencia encendieron más el fuego de sus corazones. En esta conquista pasaron muy numerosas obras y palabras, que son más para contemplación que para escritura (El Abencerraje 1965: 39-40. El subrayado es nuestro).

La cita de Tirant lo Blanc, una de las tantas que podrían provenir de los libros de caballerías, en los que el amor sensual y la infidelidad están ampliamente presentes, muestra el empleo erótico de un mueble asociado a perfumes y a una temperatura agradable: la cama es el espacio de un calor compartido en el contexto frío del invierno. El fragmento de El Abencerraje es osado fundamentalmente por lo que no dice y evoca: la «nueva experiencia» con sus sorpresas y descubrimientos, una escena más adaptada a la «contemplación», es decir al voyeurismo y no tanto a las palabras. Decir «contemplación» es invocar la magia de los cuerpos en su encuentro carnal y no la relación espiritual entre los enamorados. Y es que la cama en todas las acepciones que se le dan es mucho más el ámbito de lo corporal (donde se descansa, se duerme, se copula, se padece una enfermedad y se muere) que el espacio de lo inmaterial.

Rastrear el peso de la cama como concepto en la novela corta española del Siglo de Oro podría representar una experiencia tan rica e inmensa que un breve artículo no puede contenerla. Por esa razón me contentaré con una visión a vuelo de pájaro que quizá pueda incitar a otros más jóvenes a aventurarse entre los pliegues de las sábanas y detrás de los cortinajes que acompañan este tema.

Mi corpus de trabajo será el siguiente: Miguel de Cervantes, Novelas ejemplares (1613); Alonso Jerónimo de Salas Barbadillo, Corrección de vicios (1615) y Casa del plazer honesto (1620); Diego Ágreda y Vargas, Novelas morales, útiles por sus documentos (1620); María de Zayas y Sotomayor, Novelas amorosas y ejemplares (1637). Esta selección de cinco títulos merece una justificación. El ejemplo cervantino no podía faltar, puesto que si bien no es este autor quien inicia el género, sí es él quien le da coherencia y lo estructura en torno a una fórmula que tiene luego fortuna editorial. El caso de Salas Barbadillo me parece interesante porque encarna los balbuceos en torno a un proyecto: hay en Salas Barbadillo verdadera experimentación (novela en prosa y novela en verso, relato corto a la manera picaresca y a la manera cortesana). Salas Barbadillo camina hacia un estereotipo sin alcanzarlo, lo que quizá le confiera a su modo novelístico un particular interés. Las Novelas morales de Ágreda y Vargas constituyen ya un modelo de mercado de lo que es una colección de novelas cortas en busca de un público consensual (Copello 2008: 155-157). En cuanto a los relatos de Zayas, más alejados 
por lo que hace a su fecha de publicación (aunque muchos de ellos estarían ya listos para la imprenta hacia 1625-1626 (Olivares, en Zayas 2010: 116), tienen el interés de haber sido redactados desde una perspectiva femenina, además de su valor evidente. La muestra es entonces incompleta, pero relativamente representativa de un momento clave de un género literario. No me limitaré a tomar ejemplos en los relatos propiamente dichos sino que, a veces, evocaré la referencia a la cama en los marcos narrativos, presentes en los dos libros de Salas Barbadillo y en el de Zayas. Ágreda y Vargas, por su parte, sigue la corriente cervantina de presentar novelas no enmarcadas.

Pienso que lo primero que debe ser evocado es la cama como objeto, como mueble, referencia que no es de las más frecuentes pero que tiene su peso a la hora de auscultar el sentido del concepto en un género que no sólo explora lo social sino que a menudo lo juzga. La cama puede ser un mueble caro y ostentoso. En el marco narrativo de la Corrección de vicios se critica la abundancia en el caso de una viuda de moral dudosa después de la muerte de su marido y que ahora tiene: «...los estrados, camas y colgaduras duplicados, como pliegos que van a Indias...» (Salas Barbadillo 1615: f. 58v; modernizamos ortografía y puntuación en este caso y en los siguientes). En una novelita del mismo libro, Antes morir que decir verdad, un personaje que tiene una deuda de cuatrocientos escudos propone pagar con objetos, entre los cuales se hallan camas: «Yo al presente no me hallo con dineros para satisfacer esta partida, [...] pero aquí están estas dos piezas con las colgaduras y camas que Vs. Ms. ven, y entréguense en ellas...» (Salas Barbadillo 1615: f. 136r). En otro sentido, sin duda humorístico pero no menos cierto, la cama puede albergar bajo el colchón un tesoro, como en el caso del avaro protagonista de La mejor cura del Matasanos del mismo Salas Barbadillo:

Esta cama que veis, donde tendido estoy agora, es pobre en apariencia [...] Sabed, pues, que se cargan los colchones de mi lecho en un arca ancha y espaciosa, que dentro encierra veinte mil doblones... (Salas Barbadillo 1615: f. 116r-v).

No me parece menos significativo del lugar emblemático que ocupa la cama en las mentalidades el hecho de que la protagonista de El coche mendigón, envergonzante y endemoniado del mismo autor, obsesionada por los coches, se haga pintar un coche en la cabecera de su cama como imagen de devoción (Salas Barbadillo 1620: f. 34v).

En la orilla opuesta, la pobreza de la cama o la ausencia de ella delata avaricia o miseria. En el incipit mismo de El castigo de la miseria, de María de Zayas, se alude a un miserable hidalgo cuyo único bien material es una pobre cama, que 
además debe compartir con su padre (Zayas 2010: 253). Todavía más elocuente es el caso del protagonista de un cuentecillo incluido en el marco narrativo de $\mathrm{Co}$ rrección de vicios, de Salas Barbadillo: «Vivió en España un desdichado, humilde en nacimiento y oficio; [...] era mercader de paños, [...] vivía solo en un aposentillo pequeño, donde tenía por cama una tabla, y por cabecera una piedra. [...] Echábase desnudo y cubríase con una frazada [en lugar de sábanas]» (Salas Barbadillo 1615: f. 78r-v; el subrayado es nuestro).

Todos estos ejemplos muestran el peso que tiene la cama en el período que estudiamos, en relación con el confort y con una marca jerárquica social. Se trata de un mueble ya completamente integrado en la vida cotidiana de ciertas capas sociales a partir del Renacimiento. Y suele ser el mueble más rico de la casa, como explica Antonio Urquízar Herrera al evocar las escenografías domésticas de los nobles:

Con frecuencia este [la cama] es el mueble más rico que hay en la casa, llegándose en algunos casos, como hizo Francisco de los Cobos, a incluirlo en el mayorazgo familiar. Se trata de camas de colgaduras, que tienen aparatosos doseles y cortinajes de tejidos ricos sobre estructuras de madera pintada o materiales nobles. Además, los lechos se acompañaban de escritorios, mesas y sillas, frecuentemente decoradas con telas que hacían juego con los cortinajes de las paredes y las camas. Todo ello componía un entorno de representación que superaba la intimidad que hoy se le supone a la estancia para convertirla en uno de los lugares de socialización preferidos (Urquízar Herrera 2007: 51).

Más adelante Urquízar nos da ejemplos concretos tomados de inventarios post-mortem (Urquízar Herrera 2007: 188, 190, 191, 196, 197, 200). En un trabajo reciente, Colón Calderón presta particular atención al espacio de la alcoba y al lugar de la cama en el marco narrativo de las Novelas amorosas y ejemplares de María de Zayas. Lisis, enferma de cuartanas, preside todas las sesiones que darán lugar a la relación de maravillas o novelas desde una cama vistosa, suerte de trono, ubicada cerca del estrado (Colón Calderón 2013: 137-149). La cama (asociada a la enfermedad) se sitúa allí en un espacio que es a la vez privado y público, dentro de los límites de lo familiar. Esa cama es vistosa y ornamentada (Zayas 2010: 169-170), marca una jerarquía y, a la vez, no podemos evitar pensar en la seducción que ejerce esta dama, que no está vestida con ropa de enferma, desde ese lugar tan particular.

La cama parece ser fundamentalmente, en la novela corta, el espacio de la enfermedad que puede llevar a la muerte, la curación o el parto. Es entonces un espacio de riesgo para el cuerpo, que aparece allí como protagonista esencial. Cama y cuerpo son sitios contiguos, continente y contenido que a veces se confunden. La cama es el lugar en el que comienza la metamorfosis hacia la insania de Tomás Rodaja en El licenciado Vidriera: «Seis meses estuvo en la cama Tomás, en los 
cuales se secó y se puso, como suele decirse, en los huesos...» (Cervantes 2003: II, 82). No olvidemos que el cuerpo es un elemento ineludible en este relato. Camas y enfermos hay también en El casamiento engañoso y en Coloquio de los perros ${ }^{4}$. Y hay otros ejemplos en Antes morir que decir verdad y El gallardo montañés y filósofo cristiano de Salas Barbadillo (1615: f. 131r; 1620: f. 118v), en El premio de la virtud y castigo del vicio, El daño de los celos y El viejo enamorado de Ágreda y Vargas (1620: 91, 265-266, 673) y Aventurarse perdiendo (Zayas 2010: 186189) y El castigo de la miseria de María de Zayas (Zayas 2010: 186-189, 286).

En el caso en que la cama es el espacio de la fertilidad y de los nacimientos, poco presente en la novela corta aunque sí aparezca en la pintura religiosa ${ }^{5}$, nos encontramos con ejemplos que oscilan entre enfermedad y fertilidad porque un concepto puede enmascarar al otro. Es lo que ocurre en La ilustre fregona de Cervantes cuando una señora en hábito de peregrina llega a una posada y pasa allí varios días ocultando su parto bajo la especie de una enfermedad. Esta gran señora, que resulta ser la madre de la ilustre fregona, llega con una «rica cama» que, de alguna manera, delimita aristocráticamente el espacio en que va a producirse el parto, aunque este ocurra en una vulgar posada ${ }^{6}$. Otro ejemplo que merecería ser analizado es el de La señora Cornelia (Cervantes 2003: II, 248-253).

Siempre dentro de las acepciones privilegiadas por los lexicógrafos clásicos nos encontramos con la cama como espacio del descanso. En ella se duerme, pero también se come ${ }^{7}$. De ello hay ejemplos en diversas novelitas como La ilustre fregona (Cervantes 2003: II, 151, 153, 155, 173), Las dos doncellas (Cervantes 2003: II, 201-204), El casamiento engañoso (Cervantes 2003: II, 286), La Dama del perro muerto (Salas Barbadillo 1615: f. 42v), El escarmiento del viejo verde

4 Desde su cama de enfermo escucha el alférez Campuzano el coloquio canino (Cervantes 2003: II, 293). Por su parte, Berganza ataca a una negra lasciva y la obliga a guardar cama ocho días (Cervantes 2003: II, 322), lo que muestra que la cama puede también ser el lugar en el que se cumple una penitencia.

5 En efecto, el motivo del nacimiento de la Virgen evoca el tema del parto y le otorga a la cama un valor particular. Basten dos ejemplos distantes y significativos: El nacimiento de la Virgen de Juan Pantoja de la Cruz (1603, Museo del Prado), en el que la cama (como mueble) ocupa de manera amplia el segundo plano, y El nacimiento de la Virgen de Bartolomé Murillo (1655, Museo del Louvre), que muestra la cama y sus pliegues en un segundo plano iluminado. Hay que tener en cuenta que la historia sagrada no es temática propia de la novela corta.

6 «Traía asimismo [...] una rica cama [...] y la peregrina representaba ser una gran señora; [...] mandó que luego luego le hiciesen la cama...» (Cervantes 2003: I, 186).

7 En este sentido, es interesante notar que Juan de Zabaleta, en El día de fiesta por la mañana y por la tarde [1654 y 1660], le atribuye una importancia considerable a la cama (Zabaleta 1983: 122, $125,129,151,162,166,167,190,191,203,213,222,249,250)$. Entre sus funciones aparece la de almorzar o comer en ella (190-191, donde se refiere al glotón). Evidentemente, si el prometido Día de fiesta por la noche hubiera sido escrito, la cama hubiera tenido allí un protagonismo indudable. Baptista Remiro de Navarra, en Los peligros de Madrid [1646], no se interesa por las camas. 
(Salas Barbadillo 1615: f. 70r), el marco de Corrección de vicios (Salas Barbadillo 1615: f. 82r), Aurelio y Alejandra (Ágreda y Vargas 1620: 40) y La burlada Aminta (Zayas 2010: 222; en este caso el descanso es interrumpido por el pensamiento y las preocupaciones que impiden dormir).

Hasta ahora nos hemos limitado, pues, a enumerar ejemplos que están relacionados con las definiciones expresadas en los diccionarios de la época: la cama como sitio destinado al descanso, a la curación, a una desgracia corporal que puede llevar a la muerte.

Dentro de la acepción relacionada con lo grato (dormir, comer) se podría añadir el elemento sexual (que además puede llevar a la fertilidad). La soledad sexual de la mujer aparece condenada por la Boca de Todas Verdades en el marco de $\mathrm{Co}$ rrección de vicios:

«El hombre casado con mujer principal, que solicita otra de la misma calidad, doncella y recogida, descasa a dos mujeres: porque ciego con la pasión amorosa, no acude a las obligaciones de su casa y falta a lo más principal, viviendo su mujer propia, como quien no tiene marido, padeciendo soledad en la mesa y en la cama» (Salas Barbadillo 1615: f. 56v).

Se trata de un lugar común que también expresa María de Zayas en La fuerza del amor: «Empezó a ser ingrato, faltando a la cama y a la mesa...» (Zayas 2010: 354). Si bien el componente placentero no está expresado de manera declarada, es imposible negarlo.

Los argumentos novelescos van a apropiarse de este sentido erótico y van a desgranarlo en episodios que sin duda atraían y seducían a los lectores ${ }^{8}$. La literatura occidental ya desde sus inicios se permitía alusiones sensuales que transcurrían en el lecho. Citemos el caso de Ulises, cuyo reencuentro con Penélope, de connotaciones eróticas y conyugales, transcurre en una cama de madera de olivo9 .

Entre las novelas cervantinas es La fuerza de la sangre aquella en la que la cama adquiere un protagonismo incomparable. Ese mueble recorre el relato y es el telón de fondo de los momentos esenciales. En la cama de Rodolfo ocurre el encuentro carnal con Leocadia (Cervantes 2003: II, 79), y aparece descrita como ricamente compuesta y semejante a la de un príncipe (Cervantes 2003: II, 82). Esa alcoba que da a un jardín y, fundamentalmente, esa cama constituyen «el teatro donde se representó la tragedia de su desventura», es decir, la de Leocadia

$8 \quad$ Sobre el erotismo en la novela cortesana, véase el trabajo de Rey Hazas (1990). Se añaden allí referencias a la cama en autores que no evocamos, como Pérez de Montalbán y Camerino (Rey Hazas 1990: 273, 275) y se estudia el caso de Loubayssin de Lamarca, que desde Francia le da otra perspectiva al asunto de las sexualidades y las camas (Rey Hazas 1990: 285-286).

9 Véase una referencia a ello y unos comentarios sobre la cama como lugar de encuentro conyugal en el libro de Perrot (2009: 73-75). 
(Cervantes 2003: 83). Varios años después, la heroína puede reconocer el sitio en el que fue engendrado su hijo Luis: «...conoció la disposición de ella [la estancia], vio la ventana y la reja que caía al jardín, [...] pero lo que más conoció fue que aquella era la misma cama que tenía por tumba de su sepultura...» (Cervantes 2003: II, 87; el subrayado es nuestro). Lo que encarnaba el emblema del comienzo de la tragedia de la protagonista va a convertirse, a través de una pirueta, en lo que activa el principio del camino hacia la felicidad, ya que Leocadia y Rodolfo, que se gustan, acaban por casarse.

Infinitamente largo sería evocar el valor de la cama como lugar de ensoñaciones eróticas en El celoso extremeño del mismo autor. No solamente aquí espacio y arquitectura cobran dimensiones intensas y colocan la cama en el centro de la descripción, sino que la manipulación del espacio por parte del protagonista recuerda la arquitectura del serrallo, donde la presencia de ciertos animales machos está prohibida, así como también ciertos vegetales (los pepinos). La única presencia masculina está reducida a un eunuco recluido en un espacio intermedio, lo que también recuerda el funcionamiento del harén ${ }^{10}$. Es evidente que la representación de la cama y de sus sentidos asociados se nutre tanto de la cultura occidental como de la oriental.

Otros autores evocan el lecho como espacio del erotismo. A veces es el lugar en el que se da una confusión como resultado de una burla, según vemos en $L a$ niña de los embustes de Salas Barbadillo, que renueva un recurso también presente en la novela italiana. La víctima de Teresica: «...valiéndose [...] del tacto, y haciendo de las manos ojos, fue poco a poco tentando las paredes, hasta que encontró con los pilares de una cama, [...] y dándose mucha prisa a desnudarse, tomó posesión de las sábanas.» (Salas Barbadillo 1615: f. 183r y ss.). Es lo que podríamos llamar el episodio de la cama oscura cuyo desenlace acaba en sorpresa. Algo semejante ocurre en El premio de la virtud y castigo del vicio de Ágreda y Vargas (1620: 88-91). Y la oscuridad tiene un papel importante en El viejo enamorado del mismo autor (Ágreda y Vargas 1620: 667-668).

La cama es un sitio abiertamente erótico y placentero en La burlada Aminta de Zayas (2010: 228), y absurdamente parodiado es el escenario de una intensa desilusión erótica en El castigo de la miseria de la misma escritora, donde el avariento protagonista descubre que se ha casado con una vieja sin dientes y con escasos cabellos (Zayas 2010: 276). Varios son los ejemplos que podríamos tomar de esta escritora cuya riqueza novelística radica, según Juan Goytisolo, en las escenas y alusiones sexuales (Goytisolo 1978: 98 y pássim).

10 Sobre ello véase Perrot (2009: 173-174). En cuanto a la novelita cervantina, véanse las páginas siguientes donde la cama cobra su protagonismo, acabando por ser el espacio de la muerte (Cervantes 2003: II, 120-121, 130-132, 135). 
Me gustaría evocar, para concluir, dos ejemplos. El primero es un episodio de la novela octava de la colección de Ágreda y Vargas, El premio de la traición. No se trata de una escena de gran originalidad, pero su aspecto estereotipado muestra sin duda un recurso exitoso en términos de mercado. La criada Clara trata amores con un mulato que la visita. Desgraciadamente un día llega su señora antes de tiempo; Clara entonces «...escondió al amante entre la ropa de la cama de sus dueños...» (Ágreda y Vargas 1620: 423). Afortunadamente, este consigue luego esconderse debajo del lecho, pero se dirige hacia allí un gato, lo que complica las cosas. El marido intenta sacar al gato con una espada, sin lograrlo. Luego la señora descubre al mulato y le pide a su criada que lo saque de la habitación; no dirá nada a su marido (Ágreda y Vargas 1620: 423-430). Todo el episodio transcurre en torno a un lecho que es escenografía, decorado esencial y mueble emblemático de un erotismo doméstico. Además, quien encarna ese placer pecaminoso es un sombrío mulato.

Otro episodio extraño e interesante es el que transcurre en El prevenido engañado de María de Zayas. Doña Beatriz, noble viuda, mantiene relaciones con un esclavo negro que, moribundo, yace escondido en unas caballerizas. La escena muestra el encuentro entre la joven viuda y su amante: él se halla en la cama, ella se sienta junto a él. El negro Antonio está hastiado de las visitas y de la naturaleza viciosa de la dama (Zayas 2010: 309-311). La cama simboliza a la vez el placer sexual, la enfermedad y la muerte, como dominio de significados polivalentes que remiten siempre a lo corporal. Y como en el ejemplo anterior, el color oscuro del amante remite sin duda a una simbología moral ${ }^{11}$.

Llegando ya al final, podríamos decir que la cama es esencialmente un espacio privado e íntimo (que determinadas derivas novelescas pueden desarticular transformándolo en espacio público y vergonzante). A la vez, se carga de contenidos sociales jerárquicos, porque servirse de una cama supone estar a cierta altura del suelo, elevarse, y esa elevación puede mostrarse, además, a través de materiales ricos y ornamentos. El no tener cama o tenerla pobre evoca la indigencia y la austeridad, que también suele ser de orden sexual. Territorio del amor físico y de la sensualidad, la cama alberga a los personajes entre sábanas limpias y perfumadas: todo es agrado, aunque no siempre se diga. Evidentemente, está el lado oscuro de la enfermedad y la muerte, pero ello también puede adquirir, en la cama, rasgos protocolares elegantes y refinados. Hablamos, pues, de un espacio particularmente significativo en un género literario que nombra el placer corporal aunque lo censure. Y sin embargo no es más que un ingrediente en el horizonte de la novela corta, un detalle entre otros tantos, como la mesa, el escritorio, el florero, las misteriosas cortinas.

11 El color negro ha sido uno de los tonos emblemáticos del pecado al estar asociado a diablos, demonios y hechiceras; el recurso está presente en la Edad Media y se renueva en los siglos XVı y XVII (Pastoureau 2008: 40, 51-52, 136-139). 
Una crítica del objeto (dentro de la cual incluiríamos el estudio del mueble) puede abrir perspectivas a la hora de abordar un género literario desde un ángulo pluridisciplinar. Es solo un punto de vista, una mirada que podría inspirarse en ese parti pris des choses del que hablaba Francis Ponge. Este breve recorrido por las camas noveleras ha intentado ahondar en ese camino.

Recibido: 18/09/2014

Aceptado: 25/10/2014

\section{OBRAS CITADAS}

AlberT, Mechthild (2013). «Tipologías de la sociabilidad en la novela corta del Siglo de Oro». En Mechthild Albert (ed.), Sociabilidad y literatura en el Siglo de Oro. Madrid: Iberoamericana, pp. 277-300.

Ágreda y VARGas, Diego (1620). Novelas morales útiles por sus documentos. Madrid: Tomás Iunti [Bibliothèque Mazarine, París: 46123].

Arasse, Daniel (1996). Le détail. Pour une histoire rapprochée de la peinture. París: Flammarion.

Cervantes, Miguel de [1613] (2003). Novelas ejemplares, Harry Sieber (ed.). Madrid: Cátedra.

Colón CALDERÓn, Isabel (2013). «Narrar en corro y narrar desde un sitio especial: algunas consideraciones sobre el marco boccacciano en la novela corta española del XVII». En Isabel Colón Calderón, David Caro Bragado, Clara Marías Martínez (eds.), Los viajes de Pampinea: novella y novela española en los Siglos de Oro. Madrid: Sial Ediciones, pp. 137-149.

Copello, Fernando (2008). «Los estereotipos del hombre y de la mujer en una novela publicada en 1622: El Andrógino, de Francisco de Lugo y Dávila». Nueva Revista de Filología Hispánica, LVI, 1, pp. 155-173.

(2013). «Le fablier de Sebastián Mey. Illustration et réception». Le Fablier, 24, pp. 83-87.

Covarrubias, Sebastián [1611] (1995). Tesoro de la lengua castellana o española, Felipe C. R. Maldonado (ed.), Manuel Camarero (rev.). Madrid: Castalia.

Diccionario de Autoridades [1723] (1990). Madrid: Gredos.

El Abencerraje y la hermosa Jarifa [1565] (1965). Francisco López Estrada (ed. y pról.). Salamanca: Anaya.

García SANTo TomÁs, Enrique (coord.) (2006). Espacios domésticos en la literatura áurea. Ínsula, 714, pp. 1-28.

Goytisolo, Juan (1978). «El mundo erótico de María de Zayas». En Disidencias. Barcelona: Seix Barral, pp. 63-115.

Koper, Alejandra (2013). «Casas y aposentos». Alicia Parodi y Noelia Vitali (coord.), Misceláneas ejemplares. Algunas claves para leer la colección de novelas cervantinas. Buenos Aires: Eudeba, pp. 99-110.

Martorell, Joanot, Tirante el Blanco [1511] (1974). Martín de Riquer (ed.). Madrid: Espasa-Calpe. 
Montero Reguera, José (2006). «El nacimiento de la novela corta en España (la perspectiva de los editores)». Lectura y signo, 1, pp. 165-175.

OcAmpo, Victoria (1931). «La aventura del mueble». Sur, 1, pp. 167-174.

Pastoureau, Michel (2008). Noir. Histoire d'une couleur. París: Seuil.

Perrot, Michelle (2009). Histoire de chambres. París: Seuil.

Roubaud, Sylvia (1985). «La fôret de longue atente. Amours et mariage dans les romans de chevalerie». En Augustin Redondo (ed.), Amours légitimes, amours illégitimes en Espagne (xvie-XVIIe siècles), pp. 251-267.

Remiro de Navarra, Baptista [1646] (1996). Los peligros de Madrid. María Soledad Arredondo (ed.). Madrid: Castalia y Comunidad de Madrid.

Rey Hazas, Antonio (1990). «El erotismo en la novela cortesana». Edad de Oro, 9, pp. 271-288.

Salas Barbadillo, Alonso Gerónimo de (1615). Corrección de vicios. En que Boca de todas verdades toma las armas contra la malicia de los vicios y descubre los caminos que guian a la virtud. Madrid: Juan de la Cuesta [Biblioteca Nacional de París: R 50018]. (1620). Casa del plazer honesto. Madrid: Viuda de Cosme Delgado [Biblioteca del Arsenal, París: $8^{\circ}$ BL 29679].

Urquízar Herrera, Antonio (2007). Coleccionismo y nobleza. Signos de distinción social en la Andalucía del Renacimiento. Madrid: Marcial Pons.

Vaccaro, María Rosa (1976). Mataburro lunfa. Diccionario Lunfardo de Bolsillo escrito por María Rosa Vaccaro y dibujado por el Menchi Sábat. Buenos Aires: Torres Agüero Editor.

ZaBALETA, Juan de [1654 y 1660] (1983). El día de fiesta por la mañana y por la tarde, Cristóbal Cuevas García (ed. e intr.). Madrid: Castalia.

ZAYAS y SOTOMAYOR, María de [1637] (2010). Novelas amorosas y ejemplares. Julián Olivares (ed.). Madrid: Castalia.

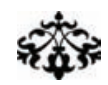

El mueble en la novela corta del Siglo de Oro: ALGUNAS REFLEXIONES EN TORNO A LA CAMA

RESUMEN: Este trabajo se interesa por un detalle en la novela corta del Siglo de Oro: la cama. La cama es a la vez un mueble y un sitio en el que transcurren acciones diversas. ¿Qué sentido y qué simbolismo tiene la cama en los relatos escritos por Miguel de Cervantes, Alonso de Salas Barbadillo, Diego de Ágreda y Vargas y María de Zayas?

Palabras Clave: Novela corta, Mueble, Cama, Sábanas, Cuerpo, Sexualidad, Sociabilidad.

\section{Furniture in Golden Age SPANISH Novel: Some Remarks about Bed}

Summary: This paper studies a detail in Golden Age Spanish novel: the bed. Bed is furniture and particularly a place where many things happen. Which is the sense and the symbolim of bed in stories written by Miguel de Cervantes, Alonso de Salas Barbadillo, Diego de Ágreda y Vargas and María de Zayas?

Keywords: Novella, Short Story, Furniture, Bed, Sheets, Body, Sexuality, Sociability. 
Evangelina Rodríguez Cuadros (Universitat de València)

Novela cortesana, novela barroca, novela corta: de la incertidumbre al canon .9

Mita Valvassori (Universidad de Los Lagos)

El modelo narrativo del Decamerón en la Edad de Oro: una vieja historia .21

Antonio Gargano (Università degli Studi di Napoli Federico II)

«Difficile est proprie communia dicere»: el género de la novella entre

Boccaccio y Cervantes

Guillermo Carrascón (Università degli Studi di Torino)

Apuntes para un estudio de la presencia de Bandello en la

novela corta del siglo XVII

Leonardo Coppola (Università degli Studi «G. d'Annunzio» di Chieti-Pescara)

La proyección de Straparola en la novela española del Siglo de Oro desde una perspectiva editorial

Mireia Aldomì García

Didactismo, género literario y lector en Giraldi Cinzio.

María Jesús Zamora (Universidad Autónoma de Madrid)

«...En tiempo menos discreto que el de agora, aunque de hombres más sabios, se

Ilamaban a las novelas cuentos». La novela corta y el cuento en el Siglo de Oro.....109

Marcial Rubio (Università degli Studi «G. d'Annunzio» di Chieti-Pescara)

La contribución de Cervantes a la novela barroca: la ejemplaridad. .125

PIERRe Darnis (Université Bordeaux Montaigne)

La fuerza de la sangre, La ilustre fregona $y$ Las dos doncellas: ¿tres tipos

folclóricos?

María Soledad ArRedondo (Universidad Complutense de Madrid)

De La gitanilla $a$ La sabia Flora malsabidilla. El género, el personaje

y el matrimonio

Antonella Gallo (Università degli Studi di Verona)

Fabulaciones en equívocos burlescos: la Chrónica del monstro imaginado (1615)

de Alonso de Ledesma y novela corta barroca

David GonZález Ramírez (Universidad de Málaga)

El filósofo del aldea (1625) de Baltasar Mateo Velázquez: recepción textual

e hipótesis autorial.

Jonathan BRAdBury (University of Exeter)

La narrativa breve en la miscelánea del siglo XVII 
Cristina Castillo Martínez (Universidad de Jaén)

«La fuente del desengaño»: de las Noches de invierno de Eslava a la Tercera

Diana de Tejeda.

María Zerari (Université Paris-Sorbonne, CLEA)

Furor in fabula: La cruel aragonesa de Castillo Solórzano (o de la dama monstruo).. 241

Giulia Giorgi (Università degli Studi di Ferrara)

Alonso de Castillo Solórzano reescritor de sí mismo: algunas notas sobre los

Escarmientos de amor moralizados y el Lisardo enamorado .257

Angela Fabris (Alpen-Adria-Universität Klagenfurt)

El diálogo con el público y los espacios reales y de maravilla en

Casos prodigiosos y cueva encantada de Juan de Piña .267

María Rocío LePe García (IES San Sebastián, Huelva)

La traducción inglesa de Hipólito y Aminta: una adaptación

con fines comerciales 281

Andrea Bresadola (Università degli Studi di Udine)

La novela española en la Italia del siglo XVII: el caso de Il Feniso

de Francisco de Quintana

José Teruel (Universidad Autónoma de Madrid)

El triunfo del Desengaño. Marco y desengaño postrero de la Parte segunda

del Sarao y entretenimiento honesto, de María de Zayas

Nieves Romero-Díaz (Mount Holyoke College)

Lecturas alternativas en la Novela del fin bueno en mal principio

de doña Ana Francisca Abarca de Bolea.

Shifra Armon (University of Florida)

Compromiso y distanciamiento en La Venus de Ferrara

de Mariana de Carvajal Saavedra

Mechthild Albert (Rheinische Friedrich-Wilhelms-Universität Bonn)

Las "noches": un subgénero novelístico en perspectiva comparada.... .365

Fernando Copello Jouanchin (Université du Maine, Le Mans)

El mueble en la novela corta del Siglo de Oro: algunas reflexiones

en torno a la cama

Ilaria Resta (Università del Salento):

De la novella al entremés pasando por la novela corta: reescrituras del cuento

La gara delle tre mogli del Cieco di Ferrara. 


\section{EDAD DE ORO}

Revista de Filología Hispánica XXXIII

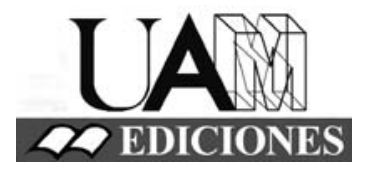




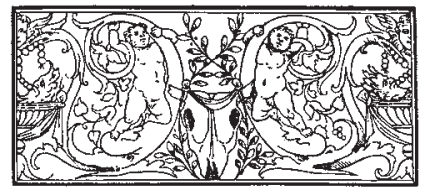

\section{Edad de Oro. Revista de Filología Hispánica}

ISSN: 0212-0429

Dirección:

Teodosio Fernández

Secretaría y edición:

José Ramón Trujillo

Coordinador del volumen XXXIII:

Rafael Bonilla Cerezo

Comité científico internacional:

Carlos Alvar (Univ. de Ginebra)

Ignacio Arellano (Univ. de Navarra)

Javier Blasco (Univ. de Valladolid)

Alberto Blecua (UAB)

Jean Canavaggio (Univ. de París X)

Laura Dolfi (Univ. de Turín)

Aurora Egido (Univ. de Zaragoza)

Víctor García de la Concha (RAE)

Luciano García Lorenzo (CSIC)

Joaquín González Cuenca (Univ. de Castilla-

La Mancha)

Agustín de La Granja (Univ. de Granada)

Begoña López Bueno (Univ. de Sevilla)

Michel Moner (Univ. de Toulouse III)

Joan Oleza (Univ. de Valencia)

Alfonso Rey (Univ. de Santiago)

Lina Rodríguez Cacho (Univ. de Salamanca)

Leonardo Romero Tobar (Univ. de Zaragoza)

Aldo Ruffinatto (Univ. de Turín)

Lía Schwartz (City University of New York)
Redacción y admisión de originales:

Teodosio Fernández

Edad de Oro

Departamento de Filología Española

Universidad Autónoma de Madrid

28049 Madrid (España)

Tfno.: +0034 914974090

correo: teodosio.fernandez@uam.es

Distribución, suscripción y venta:

Servicio de Publicaciones de la UAM

Universidad Autónoma de Madrid

28049 Madrid (España)

Intercambio de publicaciones:

Biblioteca de la Facultad de Filosofía y

Letras (UAM)

Universidad Autónoma de Madrid

28049 Madrid (España)

Han colaborado en este volumen:

Departamento de Filología Española (UAM)

Facultad de Filosofía y Letras (UAM)

Proyecto I+D FFI2013-41264-P La novela

corta del siglo XVII: estudio y edición (y II)

Edad de Oro se recoge en las siguientes bases de datos: SCOPUS, MLA Database, HLAS, Latindex, PIO-Periodical Content Index, ISOC, Dialnet, MIAR, ERIH, DICE, Sumaris CBUC, Ulrich's. Se encuentra evaluada en CIRC: A; INRECH: primer cuartil, posición 6 de 50; MIAR difusión ICDS live: 9.977; SCImago Journal \& Country Rank: H Index 2, SJR 0,101, Q4; RESH índice de impacto: 0.162; ERIH: A INT1; Carhus Plus+: B. 